\title{
Recent progress in the development of windows with vacuum glass
}

\author{
Ulrich Pont ${ }^{1, *}$, Magdalena Wölzl $^{1}$, Peter Schober $^{2}$, Shiva Najaf Khosravi ${ }^{1}$, Matthias \\ Schuss ${ }^{1}$, and Ardeshir Mahdavi ${ }^{1}$ \\ ${ }^{1}$ Dept. of Building Physics and Building Ecology, TU Wien, Karlsplatz 13, 1040 Vienna, Austria \\ ${ }^{2}$ Holzforschung Austria, Franz-Grill-Straße 7, 1030 Vienna, Austria
}

\begin{abstract}
This contribution reports on recent advances in the utilization of vacuum glass in contemporary window construction. Generally speaking, vacuum glazing consists of two glass panes with an evacuated interstitial space. To maintain the functionality of the glazing, a vacuumtight edge seal and a grid of distance-holding pillars are required. Vacuum glazing features a first-rate thermal performance as it significantly reduces conductive and convective heat transport rates. In comparison to multipane insulation glasses of comparable thermal performance, vacuum glass products feature a reduced weight and construction depth. However, the application of vacuum glass in windows requires a critical rethinking of the current practice of window construction, especially with regard to thermal bridges and the related surface condensation risk at the glass/frameconstruction joints. Specifically, the glass edge seal, which can be considered to be the weak spot of vacuum glass in terms of heat transfer, requires an insulating cover that is not provided in typical insulation glass frame configurations. Further relevant aspects to be considered include the structural stability of window constructions with vacuum glass, the acoustical performance, and issues regarding usability. In this context, the present contribution highlights the methodology and findings of two recent research projects (MOTIVE, FIVA) that addressed window construction requirements with regard to vacuum glazing deployment.
\end{abstract}

\section{Introduction \& Background}

Vacuum glass has been under development for many decades, since Zoller applied for a patent for an evacuated glass pane back in 1913 [1]. Since then, both scientific research groups and industrial development units worked on the production process of vacuum glass and, specifically, on methods of durable vacuum maintenance. Recently, vacuum glass products, particularly from Asia (China, Korea, Japan), have reached a level of development that allows for utilisation in today's building planning and delivery processes.

Vacuum glazing is commonly defined as a transparent component consisting of two parallel glass panes with a small, evacuated interstitial space. To maintain the vacuum, the glass panes are connected with a tight edge seal, typically made of glass or other gas-tight

* Corresponding author: ulrich.pont@tuwien.ac.at 
materials. To avoid any deformation of the glass panes caused by the atmospheric pressure, a grid of small distance pillars can be applied in the interstitial space. Moreover, an evacuation opening and so called getter substances can be deployed. The former is used to generate the vacuum and then closed tightly, while the latter are highly reactive chemical substances that can bind gas particles. Figure 1 illustrates these getters for two products. As vacuum glazing products nearly eliminate conductive and convective heat transfer, they are considered as an option for transparent building components with high thermal insulation requirments. In comparison to regular triple-glazing insulation glass constructions, vacuum glazing products offer similar thermal performance $\left(\mathrm{U}_{\mathrm{g}}\right.$-values of $\left.0.4-0.6 \mathrm{~W} \cdot \mathrm{m}^{-2} \cdot \mathrm{K}^{-1}\right)$, but feature lower weight and smaller dimensions.

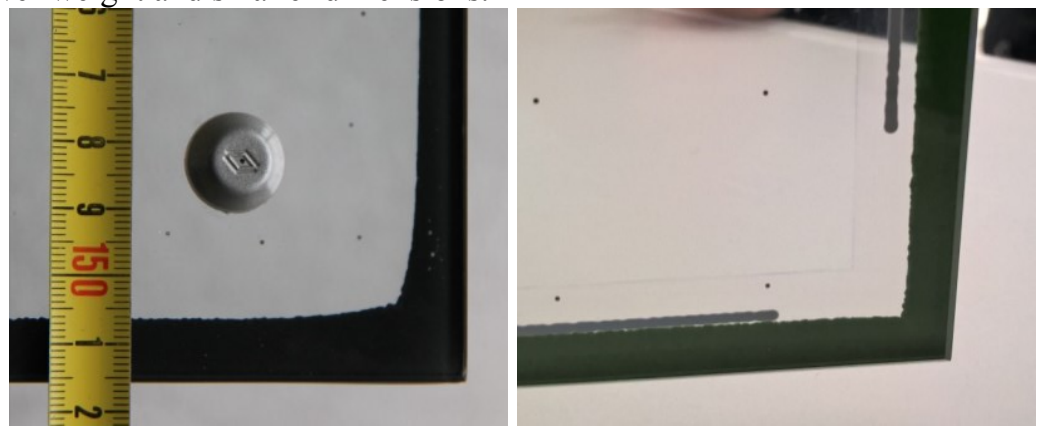

Fig. 1. Getter of a vacuum glass product made in China (left) and getter lines of a vacuum glass product from an upcoming European Vacuum glass product.

Despite multiple past and recent efforts in the field of glass product development, surprisingly few research projects address the application of glass in window constructions. The specifics of the vacuum glass require different constructions than the conventional double or triple pane windows. This offers opportunities to fundamentally overthink the way windows are designed and constructed.

The Department of Building Physics and Building Ecology of the TU Vienna, together with the Holzforschung Austria (Austrian Forest Products Research Society), has been involved in a number of research efforts toward application of vacuum glazing products in existing and new windows. Pont et al. [2][3] explored the principle application possibility of vacuum glazing products in existing casement windows. Thereby, heating demand of typical central European ("Gründerzeit") buildings was considerably reduced when one of the float glass panes was replaced by vacuum glass. Later efforts targeted the development of new window concepts employing vacuum glazing [4][5]. Figure 2 illustrates some of these efforts.

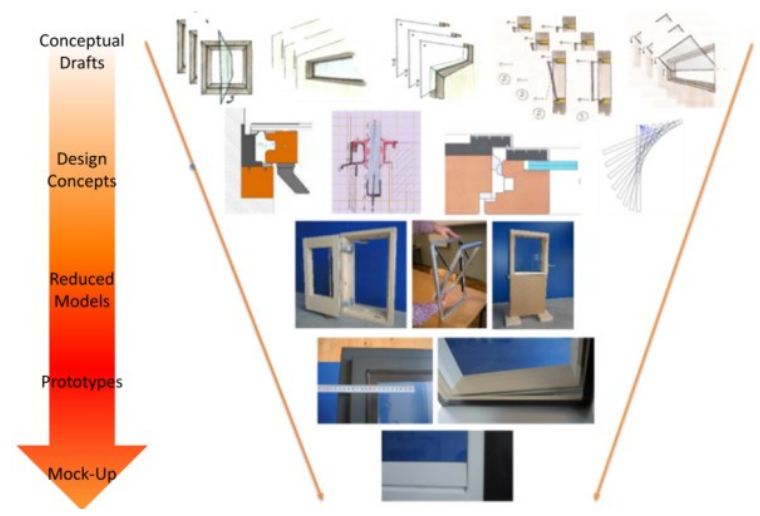

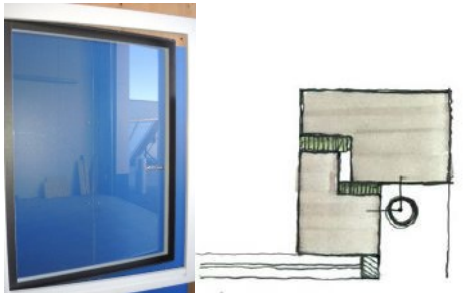

Fig. 2. Some illustrations of the development work of the project MOTIVE [4][5]. 
Aside from a study on the adaptation of vacuum glass in a typical frame used for insulation glass [6], few further efforts regarding vacuum glass application in contemporary window constructions are known to the authors.

As vacuum glass requires specifically adapted constructions, this contribution focuses on illustrating the impact of different mounting assumptions of vacuum glass in frames, and their thermal performance implications. Thereby, we do not address U-values of specific window constructions, but rather focus on the impact of different edge cover lengths and glass edge seal dimensions, as well as the impact of the application of sealing materials and encapsulated air cells in such constructions. Such conceptual considerations are of high relevance for the integration of vacuum glass products in frame constructions. The findings of this contribution are predominantly based on numeric thermal bridge simulation.

\section{Methodology}

\subsection{Vacuum glass \& its characteristics}

The vacuum glass specimen used in the present contribution consists of two $4 \mathrm{~mm}$ float glass panes with an interstitial vacuum gap of $0.15 \mathrm{~mm}$. This glass is based on the products of the Chinese company Synergy Beijing glass. Figure 3 shows the principle outline of this vacuum glass product and some general terminology (glass seal width, edge cover length). In this glass product, a dense net of distance pillars is placed ( $40 \mathrm{~mm}$ grid distance).

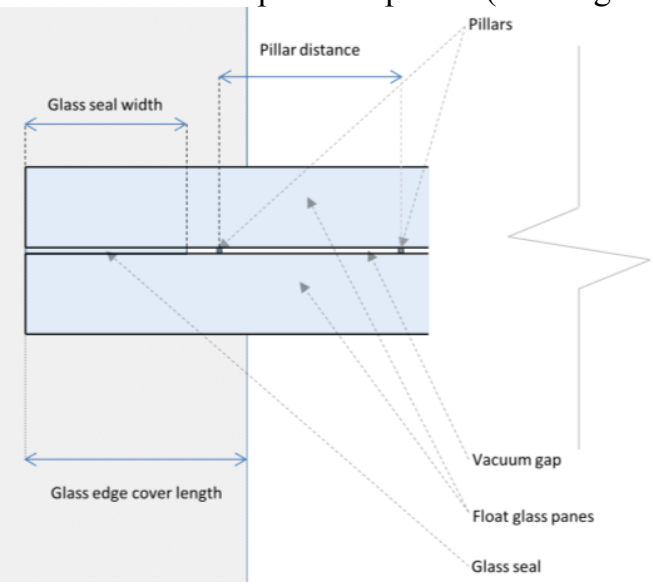

Fig. 3. Principle illustration of the vacuum glass used for evaluation purposes in this contribution.

The thermal conductivity data concerning the construction's constituents is given in Table 1 . Note that the conductivity of the vacuum gap is an approximated value attributable to radiative heat transfer, as both conductivity and conductance in the vacuum layer are practically negligible.

Table 1. Thermal conductivity of the constituents of the vacuum glass.

\begin{tabular}{|c|c|}
\hline Material & Conductivity $\left[\mathbf{W} \cdot \mathbf{m}^{\mathbf{- 1}} \cdot \mathbf{K}^{\mathbf{- 1}}\right]$ \\
\hline Glass & 1.00 \\
\hline Glass seal & 1.00 \\
\hline Vacuum gap & 0.00000975 \\
\hline Stainless steel pillars & 30.00 \\
\hline
\end{tabular}




\subsection{Simulation, Key Performance Indicators, frame/glass joint \& boundary conditions}

Simulations (steady state) were carried out with the numeric thermal bridge simulation software AnTherm (version 9.136) [7]. Steady-state boundary condition assumptions regarding indoor and outdoor temperature were assumed to be $20^{\circ} \mathrm{C}$ and $-10^{\circ} \mathrm{C}$ respectively. These conditions are in accordance with extreme boundary conditions used for surface condensation assessments, as suggested in (earlier) versions of relevant standards [8][9][10]. Simulations explored temperature distribution and associated implications for surfaces of glass and adjacent frame constructions. As to the latter, the following scenarios were considered (see Figure 4): (i) glass placed directly in a wooden frame (conductivity of the timber: $0.11 \mathrm{~W} \cdot \mathrm{m}^{-1} \cdot \mathrm{K}^{-1}$ ); (ii) glass placed into the wooden frame material surrounded by a seal material (conductivity of seal: $0.17 \mathrm{~W} \cdot \mathrm{m}^{-1} \cdot \mathrm{K}^{-1}$ ); (iii) glass placed into the wooden frame material surrounded by a seal material encompassing additional, insulating air chambers (conductivity of seal: $0.5555 \mathrm{~W} \cdot \mathrm{m}^{-1} \cdot \mathrm{K}^{-1}$ ). The wooden frame construction has a offset dimension of $38 \mathrm{~mm}$ to the inside and $30 \mathrm{~mm}$ to the outside (in relation to the corresponding glass surface). Additionally, cases were calculated, where the glass is just fitted onto a wooden frame without any glass edge cover. Both the glass edge cover lengths ( 0 to $50 \mathrm{~mm}$ in $10 \mathrm{~mm}$ steps) and the glass seal widths $(5,10,15 \mathrm{~mm})$ were varied. The generated simulation models involve a number of simplifications regarding glass/frame joints. Specifically, pillars were not included in the models, as their influence on the thermal performance of the vacuum glass was shown to be insignificant, given their very small special dimension (area per pillar $0.11 \mathrm{~mm}^{2}$ ) [11].
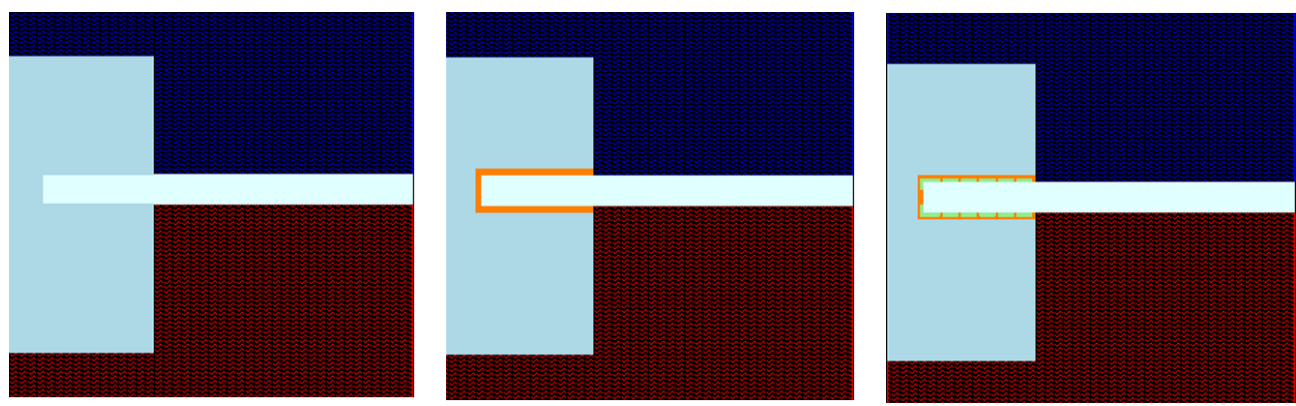

Fig. 4. Different application cases for the vacuum glass: Left: (i) direct positioning in a wooden frame ("fixed glazing"), Middle: (ii) Additional use of a sealing material; right: (iii) Use of a sealing material with air encapsulation.

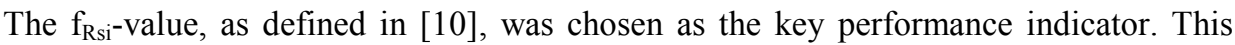
value facilitates a relative performance evaluation, as the difference between the lowest indoor surface temperature and external temperature is divided by the overall temperature difference between indoor and outdoor conditions. Austrian standardization [8] suggests 0.71 as threshold value for this indicator (details that show $f_{\text {Rsi-values of equal or below }}$ 0.71 are assumed to be susceptible to mould growth). Additionally the value and location of the lowest temperature along the inner surface $\left(\theta_{\mathrm{si}, \mathrm{min}}\right)$ of the construction is provided.

Many contemporary window constructions utilize structural adhesive bonding in frame construction. As the provision of window constructions with a full glass-only appearance from outside appears to be desired in some designs, it was decided to extend the investigation with some further scenarios: The best performing combination of parameters of the classical glass-in-frame constructions is converted to an adhesive bonding construction that has the frame construction only on one side of the vacuum glass. 


\section{Results}

\subsection{Results of the simulation efforts}

The first simulations were conducted for the cases where vacuum glass is fitted into a wooden frame with a glass edge cover of zero. Thereby, results are strongly influenced by the glass edge seal width. The $\mathrm{f}_{\mathrm{Rsi}}$-values were 0.33 ( $5 \mathrm{~mm}$ glass seal width, $\theta_{\text {si,min }}=-0.23$ $\left.{ }^{\circ} \mathrm{C}\right), 0.28\left(10 \mathrm{~mm} \theta_{\text {si,min }}=-1.55{ }^{\circ} \mathrm{C}\right)$, and $0.26\left(15 \mathrm{~mm} \theta_{\text {si,min }}=-2.30{ }^{\circ} \mathrm{C}\right)$. Thus, it is obvious that a protection of the glass edge seal is required.

In subsequent steps, the simulation results of the different parameter combinations were generated. These included cases without sealing material (i), with sealing material (ii), and with air-encapsulations in the sealing material (iii), variation of glass seal cover length, and glass seal width. Table 2 provides a comprehensive overview of these results. They suggest that it is possible, in principle, to build constructions that meet the mould-related requirements starting from $30 \mathrm{~mm}$ glass edge cover. However, in that case a very slim glass edge seal is required $(5 \mathrm{~mm})$, and the adjacent materials need to be of very low conductivity (in this case timber with a conductivity of $0.11 \mathrm{~W} \cdot \mathrm{m}^{-1} \cdot \mathrm{K}^{-1}$ ). Figure 5 a illustrates this case. Glass edge covers of $50 \mathrm{~mm}$ or more provide a good performance regarding the minimum surface temperature characteristics. Figure $5 \mathrm{~b}$ shows the best performing combination ( $5 \mathrm{~mm}$ glass edge seal width, $50 \mathrm{~mm}$ glass edge cover, adjacent material timber).
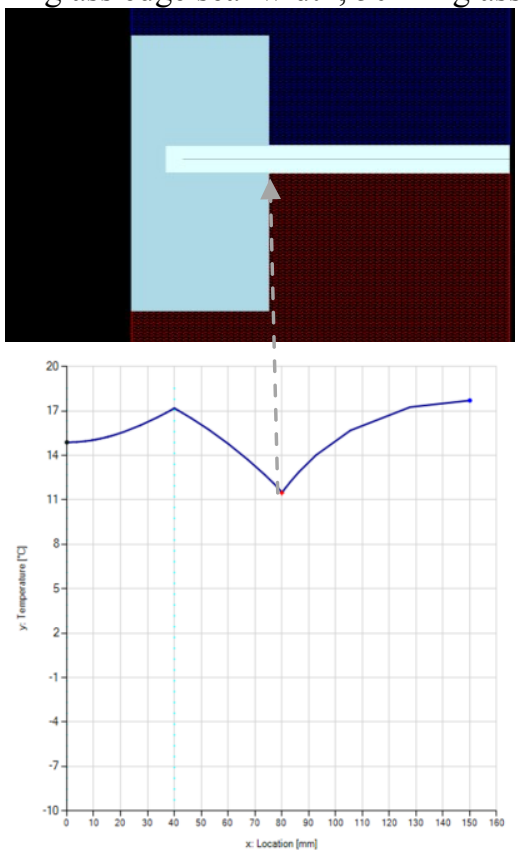

Fig. 5a. $5 \mathrm{~mm}$ glass seal width, $30 \mathrm{~mm}$ glass edge cover: $\mathrm{f}_{\mathrm{Rsi}}: 0.72, \theta_{\mathrm{si}, \min }=11.48^{\circ} \mathrm{C}(23 /$ Table 2$)$
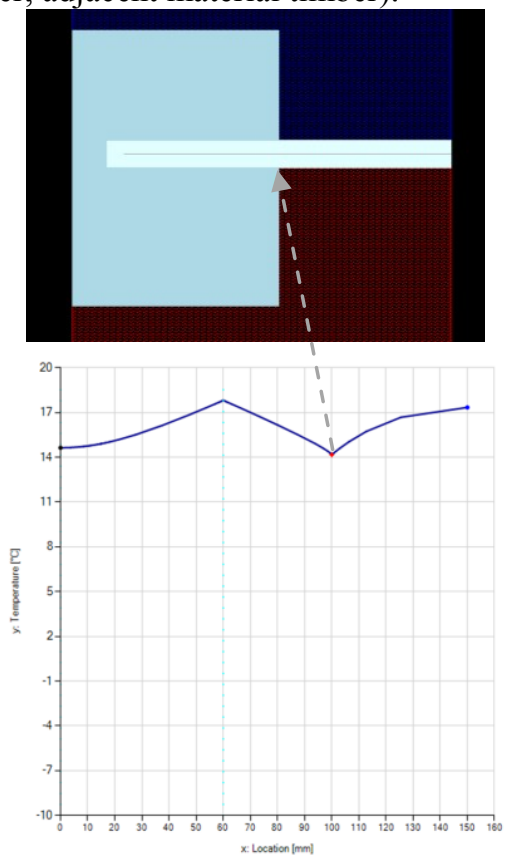

Fig. 5b. $5 \mathrm{~mm}$ glass seal width, $50 \mathrm{~mm}$ glass edge cover: $\mathrm{f}_{\mathrm{Rsi}}: 0.81, \theta_{\mathrm{si} \text { min }}=14.17^{\circ} \mathrm{C}(41 /$ Table 2$)$

In a subsequent step, the performance of single-sided framing (structural adhesive bonding) was evaluated, based on the best performing case (Fig 5b.). Thereby, a $2 \mathrm{~mm}$ adhesive bond (conductivity $0.35 \mathrm{~W} \cdot \mathrm{m}^{-1} \cdot \mathrm{K}^{-1}$ ) was positioned between vacuum glass and wooden framing (see Figure 6a and 6b). Results of these cases show that a single-sided framing is possible. 
Table 2. Result overview (bold lines comply with condensation risk standards $\rightarrow f_{R s i}>0.71$ )

\begin{tabular}{|c|c|c|c|c|c|c|}
\hline $\begin{array}{l}\stackrel{\dot{\Xi}}{\Xi} \\
\stackrel{\Xi}{\Xi}\end{array}$ & 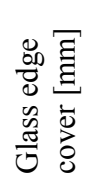 & 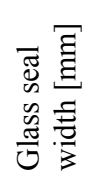 & 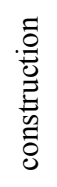 & $\begin{array}{l}\mathrm{f}_{\mathrm{Rsi}} \\
{[-]}\end{array}$ & $\begin{array}{c}\theta_{\text {si,min }} \\
{\left[{ }^{\circ} \mathrm{C}\right]}\end{array}$ & 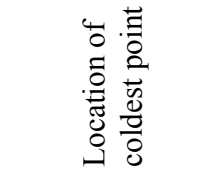 \\
\hline 1 & 0 & 5 & - & 0.33 & -0.23 & \multirow{48}{*}{ 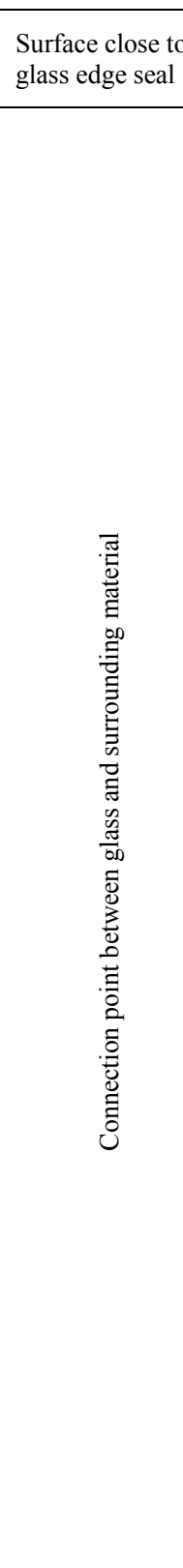 } \\
\hline 2 & 0 & 10 & - & 0.28 & -1.55 & \\
\hline 3 & 0 & 15 & - & 0.26 & -2.30 & \\
\hline 4 & 10 & 5 & W & 0.49 & 4.56 & \\
\hline 5 & 10 & 5 & $\mathrm{~S}$ & 0.48 & 4.47 & \\
\hline 7 & 10 & 5 & V & 0.48 & 4.28 & \\
\hline 8 & 10 & 10 & W & 0.38 & 1.41 & \\
\hline 9 & 10 & 10 & $\mathrm{~S}$ & 0.38 & 1.34 & \\
\hline 10 & 10 & 10 & $\mathrm{~V}$ & 0.37 & 1.23 & \\
\hline 11 & 10 & 15 & W & 0.31 & -0.56 & \\
\hline 12 & 10 & 15 & $\mathrm{~S}$ & 0.31 & -0.60 & \\
\hline 13 & 10 & 15 & $\mathrm{~V}$ & 0.31 & -0.65 & \\
\hline 14 & 20 & 5 & W & 0.63 & 8.93 & \\
\hline 15 & 20 & 5 & $\mathrm{~S}$ & 0.63 & 8.82 & \\
\hline 16 & 20 & 5 & V & 0.62 & 8.56 & \\
\hline 17 & 20 & 10 & W & 0.57 & 6.95 & \\
\hline 18 & 20 & 10 & $\mathrm{~S}$ & 0.56 & 6.84 & \\
\hline 19 & 20 & 10 & $\mathrm{~V}$ & 0.55 & 6.68 & \\
\hline 20 & 20 & 15 & W & 0.48 & 4.44 & \\
\hline 21 & 20 & 15 & $\mathrm{~S}$ & 0.48 & 4.34 & \\
\hline 22 & 20 & 15 & $\mathrm{~V}$ & 0.47 & 4.12 & \\
\hline 23 & 30 & 5 & W & 0.72 & 11.48 & \\
\hline 24 & 30 & 5 & $\mathrm{~S}$ & 0.71 & 11.36 & \\
\hline 25 & 30 & 5 & $\mathrm{~V}$ & 0.70 & 11.11 & \\
\hline 26 & 30 & 10 & W & 0.67 & 10.23 & \\
\hline 27 & 30 & 10 & $\mathrm{~S}$ & 0.67 & 10.11 & \\
\hline 28 & 30 & 10 & $\mathrm{~V}$ & 0.66 & 9.84 & \\
\hline 29 & 30 & 15 & W & 0.62 & 8.74 & \\
\hline 30 & 30 & 15 & $\mathrm{~S}$ & 0.62 & 8.62 & \\
\hline 31 & 30 & 15 & $\mathrm{~V}$ & 0.61 & 8.34 & \\
\hline 32 & 40 & 5 & W & 0.77 & 13.10 & \\
\hline 33 & 40 & 5 & $\mathbf{S}$ & 0.77 & 13.00 & \\
\hline 34 & 40 & 5 & $\mathbf{V}$ & 0.76 & 12.77 & \\
\hline 35 & 40 & 10 & W & 0.74 & 12.23 & \\
\hline 36 & 40 & 10 & $\mathbf{S}$ & 0.74 & 12.12 & \\
\hline 37 & 40 & 10 & $\mathbf{V}$ & $\begin{array}{l}0.73 \\
\end{array}$ & $\mathbf{1 1 . 8 7}$ & \\
\hline 38 & 40 & 15 & W & 0.71 & 11.24 & \\
\hline 39 & 40 & 15 & $\mathrm{~S}$ & 0.70 & 11.12 & \\
\hline 40 & 40 & 15 & $\mathrm{~V}$ & 0.70 & 10.86 & \\
\hline 41 & 50 & 5 & W & $\begin{array}{l}0.81 \\
\end{array}$ & $\mathbf{1 4 . 1 7}$ & \\
\hline 42 & 50 & 5 & $\mathbf{S}$ & 0.80 & 14.09 & \\
\hline 43 & 50 & 5 & $\mathbf{V}$ & 0.80 & 13.89 & \\
\hline 44 & 50 & 10 & W & 0.78 & 13.51 & \\
\hline 45 & 50 & 10 & $\mathbf{S}$ & 0.78 & 13.42 & \\
\hline 46 & 50 & 10 & $\mathbf{V}$ & 0.77 & 13.20 & \\
\hline 47 & 50 & 15 & W & 0.76 & 12.38 & \\
\hline 48 & 50 & 15 & $\mathbf{S}$ & 0.76 & 12.69 & \\
\hline 49 & 50 & 15 & $\mathbf{V}$ & 0.75 & 12.46 & \\
\hline
\end{tabular}




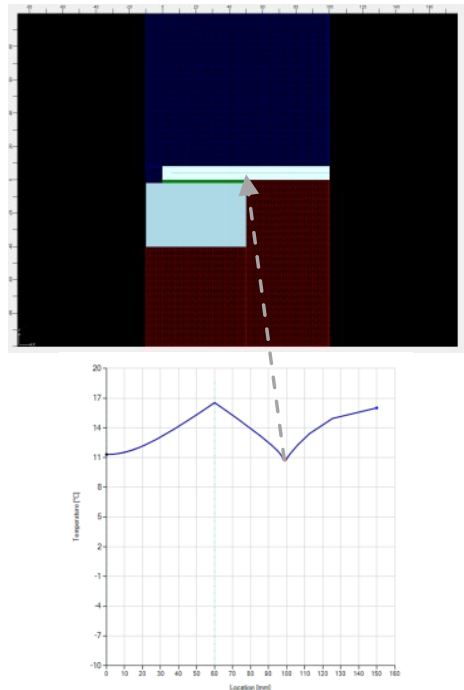

Fig. 6a. single sided frame $(50 \mathrm{~mm}$ glass edge cover, $2 \mathrm{~mm}$ adhesive bonding): $\mathrm{f}_{\mathrm{Rsi}}: 0.69, \theta_{\text {si,min }}$ $=10.79^{\circ} \mathrm{C}$

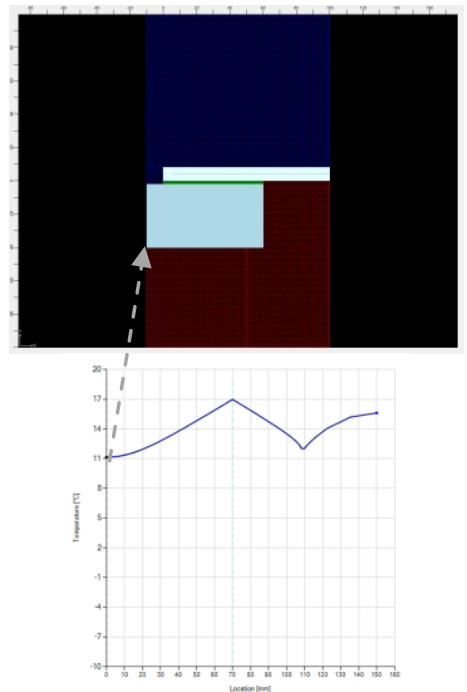

Fig. 6b. single sided frame $(60 \mathrm{~mm}$ glass edge cover, $2 \mathrm{~mm}$ adhesive bonding): $\mathrm{f}_{\mathrm{Rsi}}: 0.71, \theta_{\text {si,min }}$ $=11.15^{\circ} \mathrm{C}$

\subsection{Implications for construction}

The following construction recommendations can be derived from the findings of this contribution:

- To be on the safe side, a glass edge cover of 40 to $50 \mathrm{~mm}$ is recommended (glass in wooden frame).

- Vacuum glass panels with a smaller glass edge seal thickness require smaller glass edge cover. However, this needs to be coordinated with the structural necessities and the tightness considerations (vacuum-preservation).

- A certain minimum material thickness (roughly around $40 \mathrm{~mm}$ ) is necessary for frame materials of single-sided windows (including adhesively bond vacuum glazing).

As a case in point, the construction illustrated in Figure 7 follows the mentioned construction principles and shows a good performance.
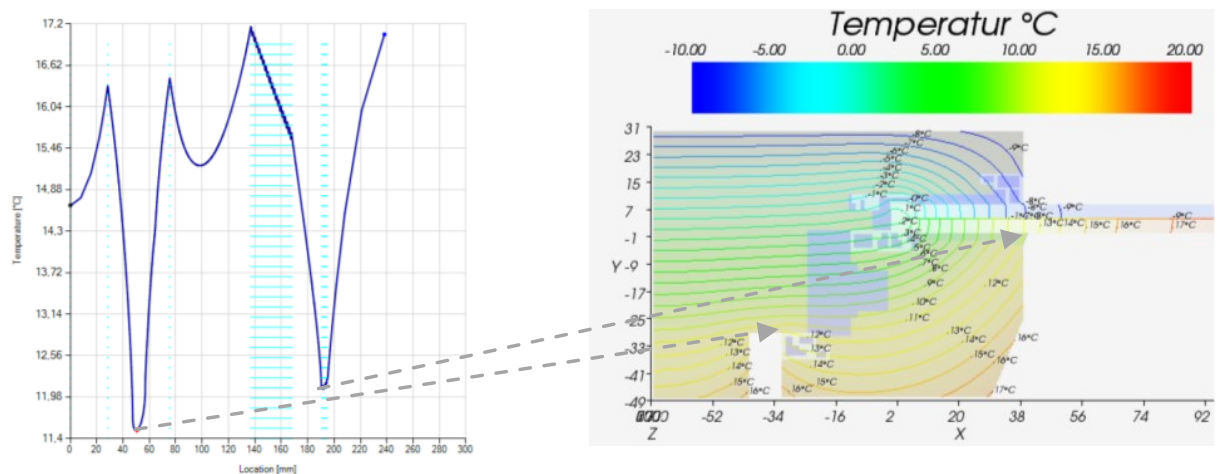

Fig. 7. Construction developed in the MOTIVE and FIVA project work (first published in [5]). 


\section{Limitations, Outlook \& Future Research}

The present contribution entailed a simulation-based approach to derive at window construction principles for windows encompassing vacuum glass. Thereby, certain parameters, such as the glass edge width and the glass edge cover were varied and analysed in view of their performance implications. Needless to say, the present study comes with a number of limitations: First of all, the construction materials of frame and vacuum glass were not varied, so that the results may provide only rough estimates for other vacuum glass panes and different frame materials. Moreover, results were generated with a numeric simulation tool focussing mostly on conductive heat transfer processes. Moreover, the simulations were performed as steady-state simulations to facilitate an assessment. As a consequence, heat storage effects in materials were neglected in these simulations. Hence, future research efforts not only need to take a closer look at heat storage as well as convective and radiative processes, but also need to include validation studies via in-situ measurements of built structures.

The research presented in this paper was in major parts funded by the Austrian Research Promotion Agency FFG in the framework of the projects VIG-SYS-RENO (FFG Proj.No. 845225, 2014-2015), MOTIVE (FFG Proj. No. 854690, 2016-2017), and FIVA (FFG Proj. No. 867352, 2018 - 2020).

\section{References}

1. A. Zoller. Hohle Glassscheibe, German patent Application No. 387655. (1913)

2. U. Pont, E. Heiduk, P. Schober, H. Pichler, F. Dolezal, O. Proskurnina, M. Schuss, C. Sustr, H Hohenstein, A. Mahdavi. "VIG-SYS-reno Sondierung von Fenstersystemen mit innovativen Gläsern, speziell Vakuum-Isoliergläsern, zur Gebäudesanierung - Berichte auf Energie- und Umweltforschung"; Final-Report for FFG - Programm Stadt der Zukunft / BMVIT;, 2018; 218 pages; Berichte aus Energie und Umweltforschung 33/2018

3. O. Proskurnina, U. Pont, A. Mahdavi: "The performance of vacuum glazing in existing window constructions: A case study"; in: "Proceedings of the 3rd Central European Symposium on Building Physics", J. Grunewald et al. (ed.); Technische Universität Dresden / Scientific Committee of the CESBP, (2016), 978-3-8167-9798-2; 435 - 440.

4. U. Pont, M. Schuss, A. Mahdavi, P. Schober, K. Hauer, C. Lux. MOTIVE - Modellierung, Optimierung, und technische Integration von Vakuumglas-Elementen. Final-Report for FFG Programm Stadt der Zukunft / BMVIT; Berichte aus Energie- und Umweltforschung 24/2018 (https://nachhaltigwirtschaften.at/resources/sdz_pdf/berichte/schriftenreihe-2018-24-motive.pdf)

5. U. Pont, M. Schuss, P. Schober, A. Mahdavi: "Conception and Assessment of Technical Solutions for the Application of Vacuum Glazing in Contemporary Window Constructions";in: "Proceedings of BauSim2018", A. Wagner, P. von Both et al. (ed.); (2018), Paper ID 1107, 8 pages.

6. I. Chmúrny, D. Szabó and M. Jurigová. Thermal Performance Testing for Window with Vacuum Glazing ; in Applied Mechanics and Materials, Volume 887, ISSN print 1660-9336, p 13 - 20.

7. AnTherm. www.antherm.eu

8. OENORM B $8110-2$ : Thermal insulation in building construction - Part 2: Water vapour diffusion and protection against condensation ÖNORM B 8110-2: 20030701

9. DIN 4108-3: Thermal protection and energy economy in buildings - Part 3: Protection against moisture subject to climate conditions - Requirements, calculation methods and directions for planning and construction

10. ÖNORM EN ISO 10211 Thermal bridges in building construction - Heat flows and surface temperatures - Detailed calculations (ISO 10211:2017), ÖNORM EN ISO 10211: 2018020

11. U. Pont, A. Mahdavi: A comparison of the performance of two- and three-dimensional thermal bridge assessment for typical construction joints;in: "Building Simulation Applications Proceedings", M Baratieri, V. Corrado, A. Gasparella, F. Patuzzi (ed.); bu.press (publisher of the Free University of Bozen-Bolzano), 3. (2017), ISSN: 2531-6702; Paper ID 75, 8 pages. 